\title{
Computational Study of Electronic Influence of Guanidine Substitution on Diels-Alder Reactions of Heterocyclic Dienes
}

\author{
Ivana Antol, Luka Barešić, Zoran Glasovac, Davor Margetić*
}

Laboratory for physical organic chemistry, Division of organic chemistry and biochemistry, Ruđer Bošković Institute, Zagreb, Croatia

* Corresponding author's e-mail address: margetid@irb.hr

RECEIVED: August 22, 2019 * REVISED: October 22, 2019 * ACCEPTED: October 22, 2019

THIS PAPER IS DEDICATED TO PROF. KATA MLINARIĆ-MAJERSKI ON THE OCCASION OF HER 70 ${ }^{\mathrm{Th}}$ BIRTHDAY

Abstract: Quantum-chemical calculations of cycloaddition properties of cyclic heterodienes substituted with guanidine functionality were carried out. Molecular and electronic structures of series of dienes (pyrrole, furan, thiophene, isoindole and 1,3-butadiene) were calculated and reactivity order established on the basis of FMO theory. Transition state calculations of model [4+2] cycloaddition reaction with acetylene indicate that guanidine substitution influences reaction barriers in moderate extent (up to $\sim 4 \mathrm{kcal} \mathrm{mol}^{-1}$ ). The substitution position plays an important role on the sign and magnitude of the effect and protonation of nitrogen possessing substituents increases reactivity of dienes.

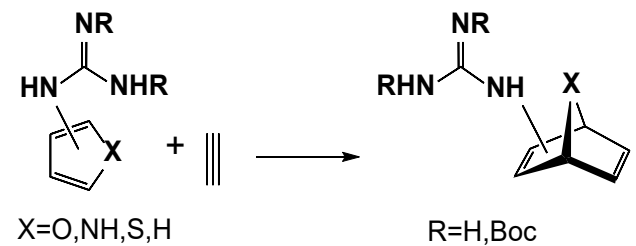

Keywords: heterocyclic chemistry, cycloaddition reactions, guanidines, organic chemistry, calculations.

\section{INTRODUCTION}

UANIDINES are strong organic bases and this physicochemical property was extensively studied, both experimentally and computationally. ${ }^{[1]}$ Also other guanidine properties such as complexation with anions ${ }^{[2]}$ or metals, ${ }^{[3]}$ biological activity ${ }^{[4]}$ as well as their use as organocatalysts ${ }^{[5]}$ are well explored. Although there are some literature examples of participation of guanidines in cycloaddition reactions, ${ }^{[6]}$ reaction mechanisms of these cycloaddition reactions were not studied in detail. As far as we are aware, the electronic effects on the cycloaddition partners (diene, dienophile, 1,3-dipole or dipolarophile), which are exerted by the guanidine functionality are not reported in the literature.

As the part of our program in quantum-chemical studies of mechanisms of cycloaddition reactions of heterocycles such as furan, ${ }^{[7]}$ pyrrole, ${ }^{[8]}$ siloles, germoles, ${ }^{[9]}$ isobenzofurans ${ }^{[10]}$ and basicities of guanidines, ${ }^{[11]}$ we have turned our attention to the synthetic utility of cycloaddition reactions to deliver guanidine compounds anchored on the polycyclic scaffolds. Synthetically powerful way to achieve this objective is the employment of Diels-Alder reaction. ${ }^{[12]}$ Here we present results of computational study of the effects of guanidine substituents on the Diels-Alder reactions of cyclic heterodienes. For this purpose, systematic survey of heterocyclic dienes bearing guanidine substituents at different positions and their acyclic butadiene analogues was carried out. The aim of this study is to assess the influence of guanidine moiety on the reactivity of cyclic heterodienes in Diels-Alder reactions. Their electronic structure of the minima and in the transition state was also analysed. 


\section{Pyrroles}

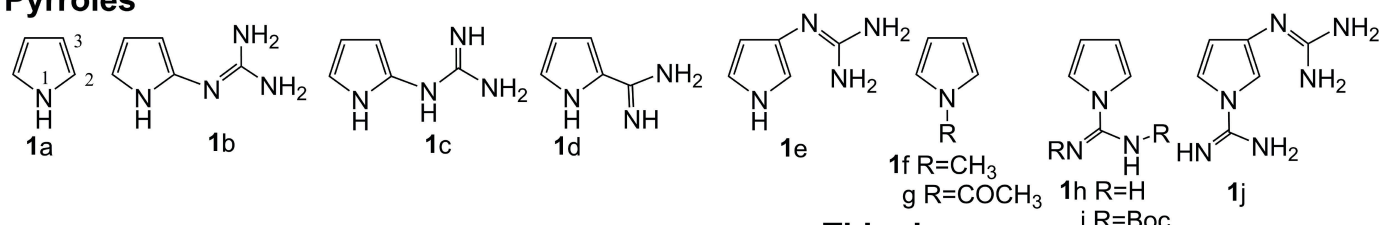

\section{Furans}<smiles>[R]c1ccco1</smiles>

2a $\mathrm{R}=\mathrm{H}$ $\mathrm{k}$ R=Me

Isoindoles<smiles></smiles>

$2 \mathrm{~b}$<smiles>C/C=C\C</smiles><smiles>C1CC2CCCC2C1</smiles>

2<smiles>N=C(N)N</smiles><smiles></smiles>

$2 e$

\section{Butadienes}

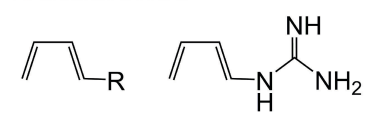

5a $\mathrm{R}=\mathrm{H}$

$\mathrm{m} \mathrm{R}=\mathrm{NH}_{2}$ $5 b$

n R=NHCOOCH
Thiophenes

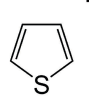

S

$3 b$<smiles>[R]C(=C)C=CC(=C)N=C(N)N</smiles>

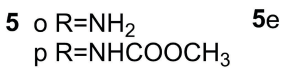

Chart 1. Dienes computed in this study.

\section{RESULTS AND DISCUSSION}

The structures of cyclic heterodienes investigated computationally are given in Chart 1. Pyrrole, furan, thiophene and isobenzofuran derivatives bearing guanidine substituents at positions 2 and 3 of the heterocycle, as well as at the $\mathrm{N}$ position of pyrrole and isoindole were calculated. In addition, 1,3-butadiene was examined, to assess the influence of aromaticity on the cycloaddition reactivity. For all dienes with nitrogen containing substituents, protonated species were calculated as well. Molecular and electronic structures of dienes in the ground state were examined, as well as the transition state energetics of model Diels-Alder reaction with acetylene.

Two tautomeric forms of 2-guanylpyrrole (1) and $\mathbf{1 c}$ ) were calculated at the B3LYP/6-31G(d) level and results show that tautomer $\mathbf{1 b}$ is considerably more stable (by $6.75 \mathrm{kcal} \mathrm{mol}^{-1}$ ), likely due to the stabilizing conjugation of guanidine substituent with the aromatic moiety. Therefore, only the more stable tautomers were calculated for all other dienes (series b). Results of the optimizations show that $\mathrm{C}_{\mathrm{gu}} \mathrm{Ngu}_{2} \mathrm{C}_{3}$ (guanidine-heterocycle) dihedral angle in neutral derivative $\mathbf{1 b}$ is around $36^{\circ}$, whereas it assumes more perpendicular conformation upon protonation. This behavior is consequence of significant conjugation of two $\pi$ systems in the neutral form which is lost upon protonation and it is in accordance to our earlier study of molecular structure of aromatic guanidines. ${ }^{[13]}$ A length of guanidine-heterocycle junction bond $\left(\mathrm{C}_{\mathrm{gu}} \mathrm{N}_{\mathrm{gu}}\right)$ is clearly indicative in this sense, changing its value from $1.385 \AA$ (neutral form) to $1.417 \AA$ (protonated form) (Figure 1). a)
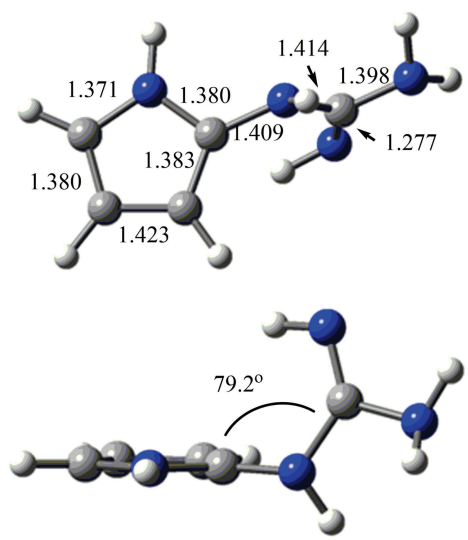

b)
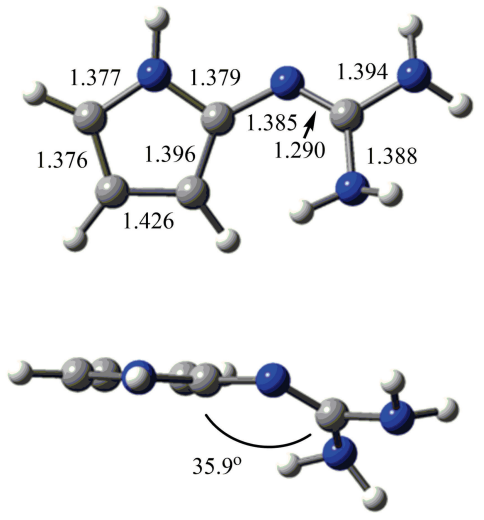

c)
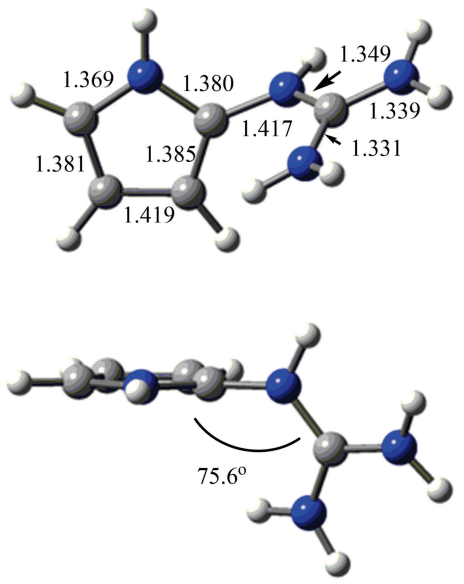

Figure 1. B3LYP/6-31G(d) optimized structures of pyrroles $1 \mathrm{c}$, 1 b and $\mathbf{1 b H}$ (top and side-view). 


\section{Molecular Orbitals Analysis}

The reactivity of various dienes participating in the DielsAlder reaction can be qualitatively determinated by the examination of frontier molecular orbitals (FMO) of dienes and dienophiles. ${ }^{[14]}$ The inspection of FMO energies of dienes (Table 1 ) indicates that when guanidine and amidine substituents are present at the 2- or 3-position of the (hetero)diene moitey, they act as the $\pi$-conjugation substituents by lowering the HOMO and increasing the
LUMO energy. ${ }^{[15]}$ The inspection of FMOs of protonated pyrroles has revealed that LUMO+2 or LUMO+1 have the appropriate orbital symmetry and coefficients are located on pyrrole moiety, thus being the most important for orbital interactions. When the substituent is protonated guanidine subunit (1c), it lowers energies of both FMOs with respect to 1a acting as an electron withdrawing substituent. In contrast, amine substitution (in $\mathbf{5 m}$ and $\mathbf{5 0}$ ) as expected is an electron donating group which led to the

Table 1. Electronic levels (eV), ${ }^{(a)}$ FMO gaps (eV), NICS values for dienes

\begin{tabular}{|c|c|c|c|c|c|c|}
\hline Diene & $\varepsilon \mathrm{HOMO}$ & $\varepsilon$ LUMO & $\Delta \varepsilon \mathrm{FMO}_{\text {diene }}{ }^{(\mathrm{d})}$ & $\Delta \varepsilon F M O I^{(\mathrm{e})}$ & $\Delta \varepsilon F M O \|^{(f)}$ & $\mathrm{NICS}(g)$ \\
\hline $1 a$ & -7.86 & 5.48 & 13.33 & 13.75 & 16.36 & -10.1 \\
\hline $1 b$ & -6.87 & 4.72 & 11.60 & 12.76 & 15.60 & -9.5 \\
\hline $1 c$ & -8.15 & 4.99 & 13.14 & 14.04 & 15.87 & -9.3 \\
\hline $1 d$ & -7.87 & 3.71 & 11.58 & 13.76 & 14.59 & -9.5 \\
\hline $1 \mathrm{e}$ & -7.14 & 5.11 & 12.26 & 13.03 & 15.99 & \\
\hline 1f & -7.78 & 5.32 & 13.10 & 13.67 & 16.20 & -9.6 \\
\hline $1 \mathrm{~g}$ & -8.49 & 3.27 & 11.76 & 14.38 & 14.15 & -8.4 \\
\hline $1 \mathrm{~h}$ & -8.13 & 4.01 & 12.14 & 14.02 & 14.89 & -8.7 \\
\hline $1 \mathrm{i}$ & -8.29 & 2.53 & 10.46 & 14.18 & 13.41 & -7.7 \\
\hline $1 \mathrm{j}$ & -7.36 & 3.95 & 11.31 & 13.25 & 14.83 & \\
\hline $1 \mathrm{bH}$ & -11.96 & $0.23(1.21)^{(\mathrm{h})}$ & 12.19 & 17.85 & $11.11(12.09)^{(j)}$ & -9.5 \\
\hline $1 \mathrm{dH}$ & -12.79 & $-2.05(1.54)^{(h)}$ & 10.74 & 18.68 & $8.83(12.42)^{(j)}$ & -9.3 \\
\hline $1 \mathrm{eH}$ & -11.90 & $0.62(1.57)^{(\mathrm{h})}$ & 11.98 & 17.79 & $11.50(12.45)^{(j)}$ & \\
\hline $1 \mathrm{hH}$ & -12.88 & $-1.58(1.36)^{(\mathrm{h})}$ & 11.29 & 18.77 & $9.30(12.24)^{(j)}$ & -7.4 \\
\hline $1 \mathrm{iH}$ & -12.33 & $-1.86(1.03)^{(\mathrm{i})}$ & 10.46 & 18.22 & $9.02(11.91)^{(k)}$ & -6.9 \\
\hline $1 \mathrm{jH}(\mathrm{N})^{(\mathrm{b})}$ & -11.03 & $-1.11(1.80)^{(\mathrm{h})}$ & 9.92 & 16.92 & $9.77(12.68)^{(j)}$ & \\
\hline $1 \mathrm{jH}(3)^{(\mathrm{c})}$ & -11.86 & 0.35 & 12.20 & 17.75 & 11.23 & \\
\hline $2 a$ & -8.54 & 4.63 & 13.17 & 14.43 & 15.51 & -9.4 \\
\hline $2 b$ & -7.34 & 4.27 & 11.61 & 13.23 & 15.15 & -7.9 \\
\hline $2 e$ & -7.74 & 4.43 & 12.17 & 13.63 & 15.31 & \\
\hline $2 k$ & -8.19 & 4.67 & 12.86 & 14.08 & 15.55 & -8.6 \\
\hline 21 & -8.42 & 4.46 & 12.88 & 14.31 & 15.34 & -8.7 \\
\hline $2 \mathrm{bH}$ & -12.62 & -0.01 & 12.61 & 18.51 & 10.87 & -8.8 \\
\hline $2 \mathrm{eH}$ & -12.59 & 0.25 & 12.85 & 18.48 & 11.13 & \\
\hline $2 \mathrm{IH}$ & -11.81 & 0.21 & 12.02 & 17.70 & 11.09 & -8.8 \\
\hline $3 a$ & -8.79 & 3.58 & 12.37 & 14.68 & 14.46 & -10.2 \\
\hline $3 b$ & -7.47 & 3.49 & 10.96 & 13.36 & 14.37 & -7.8 \\
\hline $3 e$ & -7.88 & 3.60 & 11.47 & 13.77 & 14.48 & \\
\hline 31 & -8.69 & 3.43 & 12.12 & 14.58 & 14.31 & -9.7 \\
\hline $3 \mathrm{bH}$ & -12.72 & -0.66 & 12.06 & 18.61 & 10.22 & -9.4 \\
\hline $3 \mathrm{eH}$ & -12.67 & -0.39 & 12.28 & 18.56 & 10.49 & \\
\hline $3 \mathrm{HH}$ & -11.98 & -0.02 & 11.96 & 17.87 & 10.86 & -9.5 \\
\hline $4 a$ & -6.63 & 3.17 & 9.80 & 12.52 & 14.05 & -13.7 \\
\hline $4 \mathrm{~h}$ & -8.61 & 2.56 & 11.16 & 14.50 & 13.44 & -11.6 \\
\hline $4 \mathrm{hH}$ & -10.76 & -2.12 & 8.64 & 16.65 & 8.76 & -9.2 \\
\hline $5 a$ & -8.77 & 3.46 & 12.24 & 14.66 & 14.34 & \\
\hline $5 b$ & -7.29 & 3.39 & 10.68 & 13.18 & 14.27 & \\
\hline $5 e$ & -8.15 & 3.57 & 11.71 & 14.04 & 14.45 & \\
\hline $5 m$ & -7.62 & 3.99 & 11.61 & 13.51 & 14.87 & \\
\hline $5 n$ & -8.02 & 3.45 & 11.47 & 13.91 & 14.33 & \\
\hline 50 & -8.23 & 3.76 & 11.99 & 14.12 & 14.64 & \\
\hline $5 p$ & -8.50 & 3.42 & 11.91 & 14.39 & 14.30 & \\
\hline $5 \mathrm{bH}$ & -12.17 & -0.91 & 11.26 & 18.06 & 9.97 & \\
\hline $5 \mathrm{eH}$ & -12.92 & -0.83 & 12.09 & 18.81 & 10.05 & \\
\hline $5 \mathrm{mH}$ & -13.50 & -1.41 & 12.09 & 19.39 & 9.47 & \\
\hline $5 \mathrm{nH}$ & -13.31 & -1.50 & 11.81 & 19.20 & 9.38 & \\
\hline $50 \mathrm{H}$ & -12.91 & -1.17 & 11.74 & 18.80 & 9.71 & \\
\hline $5 \mathrm{pH}$ & -13.62 & -1.46 & 12.16 & 19.51 & 9.42 & \\
\hline
\end{tabular}

(a) RHF/6-31G(d)//B3LYP/6-31G(d); (b) $1 \mathrm{j}$ protonated at substituent on pyrrole nitrogen; (c) 1 h protonated at substituent at position 3-; (d) $\Delta \varepsilon \mathrm{FMO}_{\text {diene }}=\varepsilon \mathrm{HOMO}_{\text {diene }}$

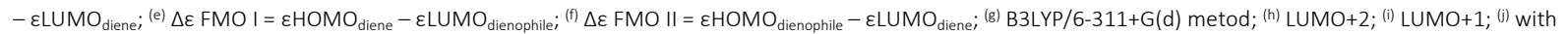
respect to LUMO+2; ${ }^{(k)}$ with respect to LUMO+1 


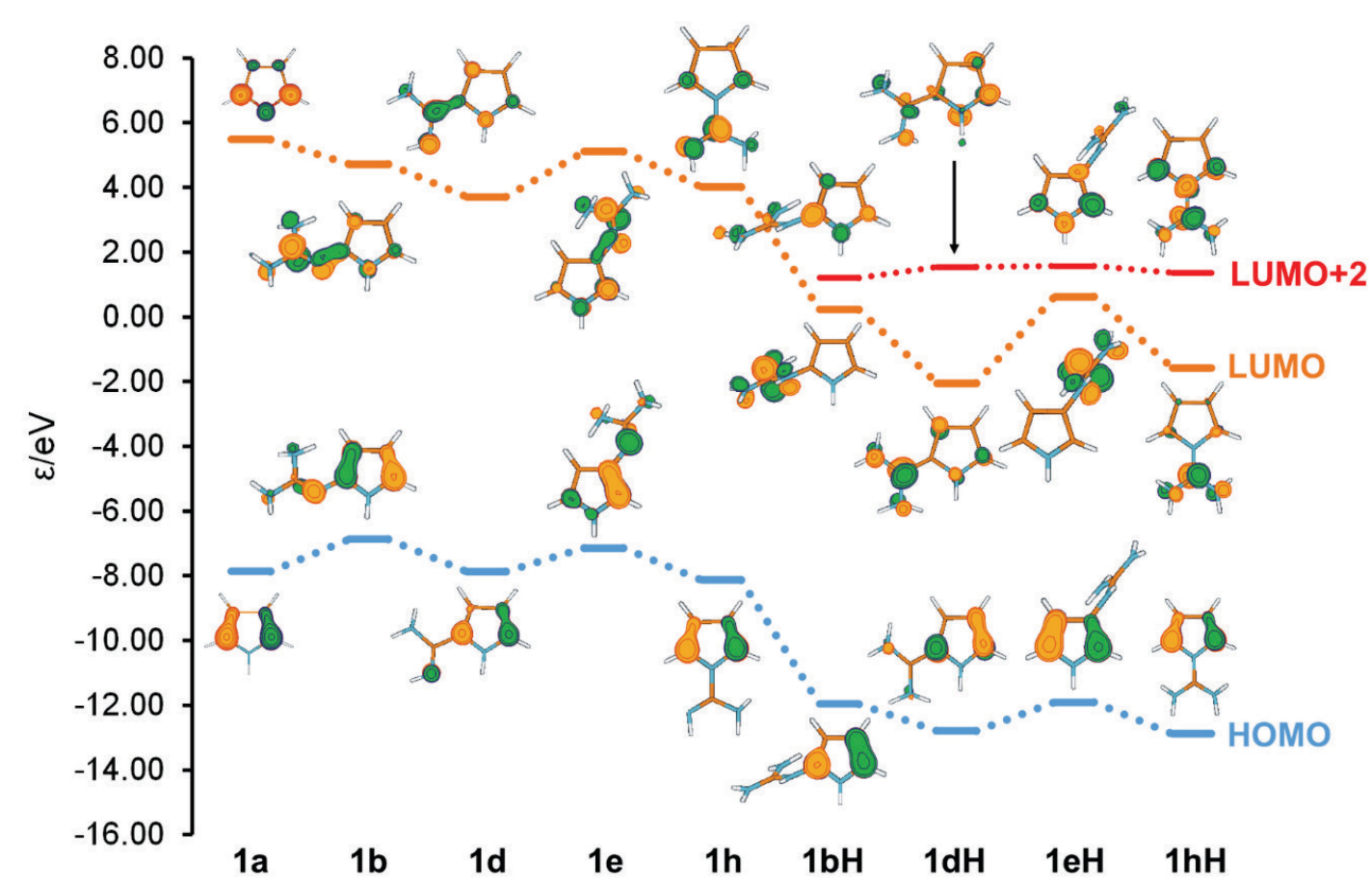

Figure 2. Energy levels $(\varepsilon)$ of HOMO and LUMO orbitals of selected pyrroles and their protonated forms calculated by the RHF/631G(d)//B3LYP/6-31G(d) method.

increase of energies of FMOs. Protonation of the nitrogen atom of the $\mathrm{N}$-containing substituents of dienes (guanidine, amidine or amine) results in a significant increase in the electronegativity of the substituent and lowering of the MO energies of the dienes (i.e. acting as electron withdrawing groups, Figure 2). Reactivity order predicted for substituents on pyrrole nitrogen atom (Figure 2 ) is in good accordance to the literature. $[8,16,17]$ Furthermore, the evaluation of FMO energies of dienes and acetylene reveals that Diels-Alder cycloadditions of neutral dienes are normal electron demand reactions ( $\Delta \varepsilon \mathrm{FMO} \mathrm{I}$, a $\mathrm{HOMO}_{\text {diene- }} \mathrm{LUMO}_{\text {dienophile }}$ stabilizing interaction is greatest), whereas Diels-Alder reactions of protonated dienes are inverse electron demand reactions ( $\Delta \varepsilon$ FMO II, $\mathrm{LUMO}_{\text {diene }}-\mathrm{HOMO}_{\text {dienophile }}$ interaction is greatest). ${ }^{[18]}$ The FMO theory predicts that the pair of cycloaddends showing the smallest gap between energy levels of the HOMO and LUMO orbitals with the proper orbital symmetry ( $\Delta \varepsilon$ FMO) will be the most reactive. The $\Delta \varepsilon \mathrm{FMO}$ II values for inverse electron demand reactions are relatively smaller than for neutral counterparts ( $\triangle \varepsilon \mathrm{FMO}$ I) suggesting that protonated dienes are generally more reactive. The inspection of FMO energies in Table 1 indicates that the most reactive diene in the DA reaction with acetylene should be the isoindole $4 a$ for neutral dienes and substituted isoindole $4 \mathrm{hH}$ for protonated dienes. According to the same FMO analysis, the least reactive is the thiophene $\mathbf{3 a}$, whereas in protonated series the lowest reactivity is predicted for pyrrole $1 \mathbf{j H} 3$. The reactivities of (hetero)dienes predicted by FMO theory were compared to their aromaticity estimated as NICS values (Table 1) and correlation was not found. The FMO theory could be predictive for reactivity only in the cases when influences other than frontier orbital interactions are constant, or are linearly related to energies of FMOs. ${ }^{[19,20]}$ However, the linear correlations of electronic structure of studied dienes (FMOs) with their cycloaddition reactivity (activation energies, Table 2, see also next section) could not be established.

\section{Transition State Calculations}

Combined influence of interacting molecular orbitals, stereoelectronic effects, aromaticity, stability of reactants and products could be more accurately assessed from transition state calculations. For this purpose, model $\pi\left[\pi 4_{s}+\pi 2_{s}\right]$ cycloaddition reaction of dienes with acetylene was used and the results of transition state calculations are summarized in Table 2. Most of the calculated reactions are thermodynamically favorable with negative enthalpy (butadienes are highly exothermic), while cycloaddition of 1d is endothermic. Protonation further increases the exothermicity of the reactions.

Representative geometries of transition states for Diels-Alder reactions of studied dienes with acetylene are shown in Figure 3. The inspection of TSs indicates that all 
a)

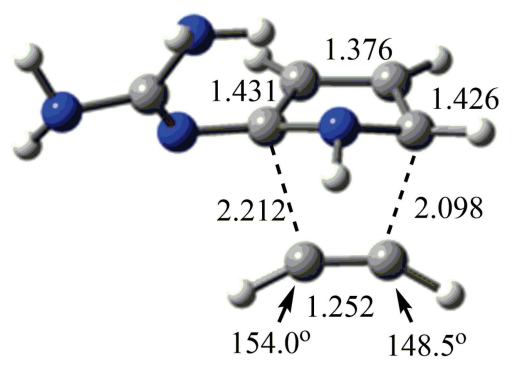

c)

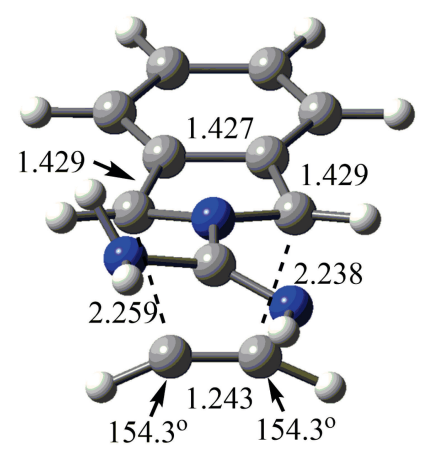

b)

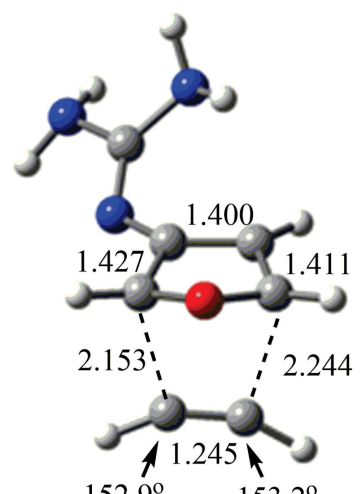

d)

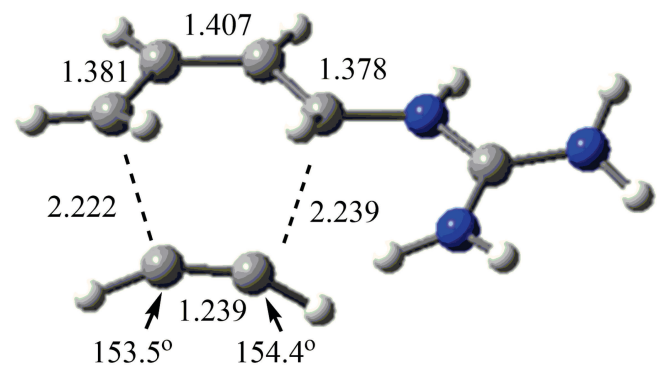

Figure 3. The B3LYP/6-31G(d) transition structures of $\left[\pi_{s} 4_{s}+\pi_{s} 2_{s}\right.$ cycloaddition reactions between acetylene and a) 1b, b) $\left.3 b, c\right)$ 4d and d) 5b. Geometries are given in $\AA$ and deg.

Table 2. B3LYP/6-31G(d) Activation energies of Diels-Alder reactions with acetylene(a)

\begin{tabular}{|c|c|c|c|c|c|c|c|c|c|}
\hline Diene & $E_{\mathrm{a}}$ & $\Delta E_{\mathrm{a}^{1}}{ }^{(\mathrm{b})}$ & $\mathrm{E}_{a} \mathrm{H}^{+}$ & $\Delta E_{\mathrm{a}}^{2}$ (c) & Diene & $E_{a}$ & $\Delta E_{\mathrm{a}}{ }^{1 \text { (b) }}$ & $E_{a} H^{+}$ & $\Delta E_{\mathrm{a}^{2}}{ }^{\text {(c) }}$ \\
\hline $1 a$ & 32.36 & & & & $2 a$ & 28.83 & & & \\
\hline $1 b$ & 35.22 & 2.86 & 30.09 & -5.13 & $2 b$ & 31.47 & 2.64 & 25.77 & -5.70 \\
\hline $1 c$ & 34.04 & 1.68 & 30.09 & -3.95 & & & & & \\
\hline $1 d$ & 36.50 & 4.14 & 34.16 & -2.34 & & & & & \\
\hline $1 e$ & 28.31 & -4.05 & 32.61 & 4.30 & $2 e$ & 25.37 & -3.46 & 26.03 & 0.66 \\
\hline $1 f$ & 31.83 & -0.53 & & & & & & & \\
\hline $1 \mathrm{~g}$ & 31.69 & -0.67 & & & & & & & \\
\hline $1 \mathrm{~h}$ & 32.37 & 0.01 & 26.58 & -5.79 & & & & & \\
\hline $1 \mathrm{i}$ & 29.92 & -2.44 & 25.86 & -4.06 & & & & & \\
\hline $1 \mathrm{j}$ & 29.18 & -3.18 & $24.71^{\text {(d) }}$ & -4.47 & & & & & \\
\hline \multirow[t]{3}{*}{$1 \mathrm{j}$} & & & $31.41^{(\mathrm{e})}$ & 2.23 & & & & & \\
\hline & & & & & $2 k$ & 29.23 & 0.40 & & \\
\hline & & & & & 21 & 27.96 & -0.87 & 26.22 & -1.74 \\
\hline $3 a$ & 38.09 & & & & $5 a$ & 20.67 & & & \\
\hline $3 b$ & 37.48 & -0.61 & 35.91 & -1.57 & $5 b$ & 20.87 & 0.20 & 19.29 & -1.58 \\
\hline $3 e$ & 34.73 & -3.36 & 34.72 & -0.01 & $5 e$ & 21.25 & 0.58 & 15.34 & -5.91 \\
\hline \multirow[t]{5}{*}{31} & 37.20 & -0.89 & 36.93 & -0.27 & & & & & \\
\hline & & & & & $5 \mathrm{~m}$ & 21.31 & 0.64 & 17.40 & -3.91 \\
\hline & & & & & $5 n$ & 21.00 & 0.33 & 18.70 & -2.30 \\
\hline & & & & & $5 \mathrm{~m}$ & 21.99 & 1.32 & 15.25 & -6.74 \\
\hline & & & & & $5 n$ & 20.62 & -0.05 & 15.11 & -5.51 \\
\hline $4 a$ & 23.42 & & & & & & & & \\
\hline $4 \mathrm{~h}$ & 23.17 & -0.25 & 17.69 & -5.48 & & & & & \\
\hline
\end{tabular}

(a) energies are given in kcal mol-1; (b) $\Delta E_{\mathrm{a}}{ }^{1}=\left(E_{\mathrm{a}}{ }^{-} E_{\mathrm{a}}\right.$ (parent unsubstituted heterocycle $\left.)\right)^{\text {(c) }} \Delta E_{\mathrm{a}}{ }^{2}=\left(E_{\mathrm{a}}-E_{a} H^{+}\right)$difference of neutral and protonated reactions; (d) protonation of guanidine subunit at $N$-position of pyrrole; (e) protonation of guanidine subunit at position 3 of pyrrole 
structures resemble a synchronous, concerted $\left[\pi 4_{s}+{ }_{\pi} 2_{s}\right]$ process. The most informative geometrical feature of TSs are the lenghts of the two new forming $\mathrm{C}-\mathrm{C}$ bonds. These values vary from 1.955 to $2.439 \AA$, which are within the usual values for pericyclic reactions ${ }^{[21]}$ and are similar to values obtained by Morokuma for butadiene. ${ }^{[22]}$ The degree of asynchronicity $(\Delta d),{ }^{[23]}$ defined as the difference of lengths of two new forming $C-C$ bonds $\left(\Delta d=d_{1}-d_{2}\right)$ is small, varying from 0 to $0.275 \AA$, and transition state structures for protonated reactions on average show larger $\Delta d$. Interestingly, dihedral angle of guanidine substituents and (hetero)aromatic ring does not changes significantly along the reaction paths, both for neutral and protonated species.

The location of transition states for model DielsAlder reaction of all heterocyclic dienes with acetylene enabled us to study the influence of guanidine substitution on activation energies (Table 2). Obtained B3LYP/6-31G(d) activation energies are in $15.11-38.09 \mathrm{kcal} \mathrm{mol}^{-1}$ range. ${ }^{[24]}$ Comparison of $E_{\mathrm{a}} \mathrm{s}$ in Figure 4 reveals general trends in reactivity of various dienes: butadienes > isoindoles > furans $>$ pyrroles $>$ thiophenes and the predicted reactivity order of parent unsubstituted molecules is $\mathbf{5 a}>\mathbf{4 a}>\mathbf{2 a}>$ 1a $>\mathbf{3 a}$ is in accordance with experimental results of relative reactivity ${ }^{[25]}$ of furan, pyrrole, thiophene and butadiene and increase of reactivity by benzannulation of isobenzo species. ${ }^{[26,27]}$

The comparison of the $E_{\mathrm{a}}$ of neutral substituted dienes (Figure 4) revealed that the most reactive dienes, isoindole and butadiene experience the smallest changes by the substitution (maximum $E_{\mathrm{a}}$ difference was predicted for butadiene 5o). On the other hand, pyrrole, furan and thiophene $E_{\mathrm{a}}$ are more affected by the substituents (maximum $E_{\mathrm{a}}$ difference is $4.14 \mathrm{kcal} \mathrm{mol}^{-1}$ for pyrrole $1 \mathrm{~d}$ ). For our study, the most important are effects imposed by guanidine substituents. The introduction of guanidine at

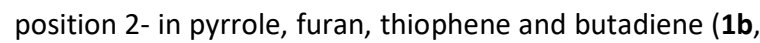
$\mathbf{2 b}, \mathbf{3 b}, \mathbf{5 b}$ ) affects differently the $E_{\mathrm{a}}$ : it is increased for pyrrole and furan by the same extent, there is almost no change in butadiene, whereas in the case of thiophene $E_{\mathrm{a}}$ decreases. The presence of guanidine group in position 3of pyrrole, furan, thiophene and butadiene $(\mathbf{1 e}, \mathbf{2 e}, \mathbf{3 e}, \mathbf{5 e})$ has different effects on $E_{\mathrm{a}}$. Calculations indicate that $E_{\mathrm{a}}$ decreases significantly for heterocycles pyrrole, furan, and thiophene (1e, 2e and $\mathbf{3 e}$ ), while small increase for butadiene $\mathbf{5 e}$ was predicted.

The consequence of other substituents was also evaluated. Amidine 2-substitution of pyrrole $\mathbf{1 d}$ increases $E_{a}$, which is similar trend and magnitude as observed for 2guanidine substituent. On the other hand, the presence of amidine or Boc-protected amidine substituents on the pyrrole nitrogen has either no effect (1h), or decreases $E_{\mathrm{a}}$ (1i, $\mathbf{1 j}$ and $\mathbf{4 h}$ ). While amidine substituents on pyrrole have significant effect, in the case of much more reactive isoindole this effect is negligible. The guanidine substitution effect in $\mathbf{1 h}$ and $\mathbf{1 e}$ are reflected as the sum of two substituents on $\mathbf{1} \mathbf{j}$. The effects of guanidine and amidine groups could be compared to amino and $\mathrm{NHCOOCH}_{3}$ substitutions and follow the same trend, the amino and $\mathrm{NHCOOCH}_{3}$ substitutions in butadiene have only small increasing effect on $E_{a}$. Finally, the 2- $\mathrm{CH}_{2}$ guanidine substituent in furan $\mathbf{2 l}$ and thiophene $\mathbf{3 l}$ modestly decreases $E_{\mathrm{a}}$, which is an opposite effect than 2methylfuran $\mathbf{2 k}$ inducing a slight increase of $E_{\mathrm{a}}$, indicating some electronic influence of guanidine substituent through $-\mathrm{CH}_{2}-$ bond on furan moiety.

Due to high basicity of guanidines, it is likely that these dienes are going to be protonated. The effect of protonation on the $E_{\mathrm{a}}$ was estimated as difference between activation energies of neutral and protonated diene $\Delta E_{\mathrm{a}}{ }^{2}=$ $\left(E_{\mathrm{a}}-E_{a} H^{+}\right)$and illustrated in Figure 4. In general, protonation of nitrogen-containing substituents (guanidine, amidine and $\mathrm{NH}_{2}$ ) led to decrease of activation energies in comparison to neutral forms (largest decrease is $6.74 \mathrm{kcal}$ $\mathrm{mol}^{-1}$ estimated for 5o). The exceptions are guanidine substitution in the position 3- of pyrrole and furan ring (1e, $\mathbf{1 j 3}$ and $2 \mathrm{e}$ ) in which $E_{\mathrm{a}}$ rises. On the other hand, this $E_{\mathrm{a}}$ increase upon protonation was not found for the corresponding thiophene and butadiene derivatives (3e and 5e). Calculated decrease of $E_{\mathrm{a}} \mathrm{s}$ upon protonation (i.e. increase in reactivity) is in full accordance with FMO predictions of higher reactivity for protonated dienes (and change to inverse electron demand mode) due to lowered LUMO energies and smaller FMO gap ( $\triangle \varepsilon F M O I I)$. These theoretical findings are conforming to literature calculations for protonated $\mathrm{N}$-methylpyrrole which predicted lowering of the activation barrier ${ }^{[28]}$ and computational and experimental results for $\left[{ }_{\pi} 4_{s}{ }^{+}+{ }_{\pi} 2_{s}\right]$ cycloaddition reactions of methylated 2-butenone with ethyl vinyl ether ${ }^{[29]}$ and reaction of $\mathrm{N}$-protonated 2-azabutadiene with cyclopentadiene. ${ }^{[30]}$

\section{CONCLUSION}

Calculations indicate that the diene substitution by guanidines has various effects on the reactivity of dienes in Diels-Alder reaction, which depends on the nature of diene and the substituent position on the diene moiety. In most cases, substituents have minor or modest effect on activation energies $E_{\mathrm{a}}$. Protonation of nitrogen-containing substituents on dienes in general leads to an increase of reactivity. Values of $E_{\mathrm{a}}$ indicate that most of the cycloaddition reactions of studied dienes are experimentally feasible, ${ }^{[31]}$ especially if model acetylene is replaced by more reactive dienophiles. 


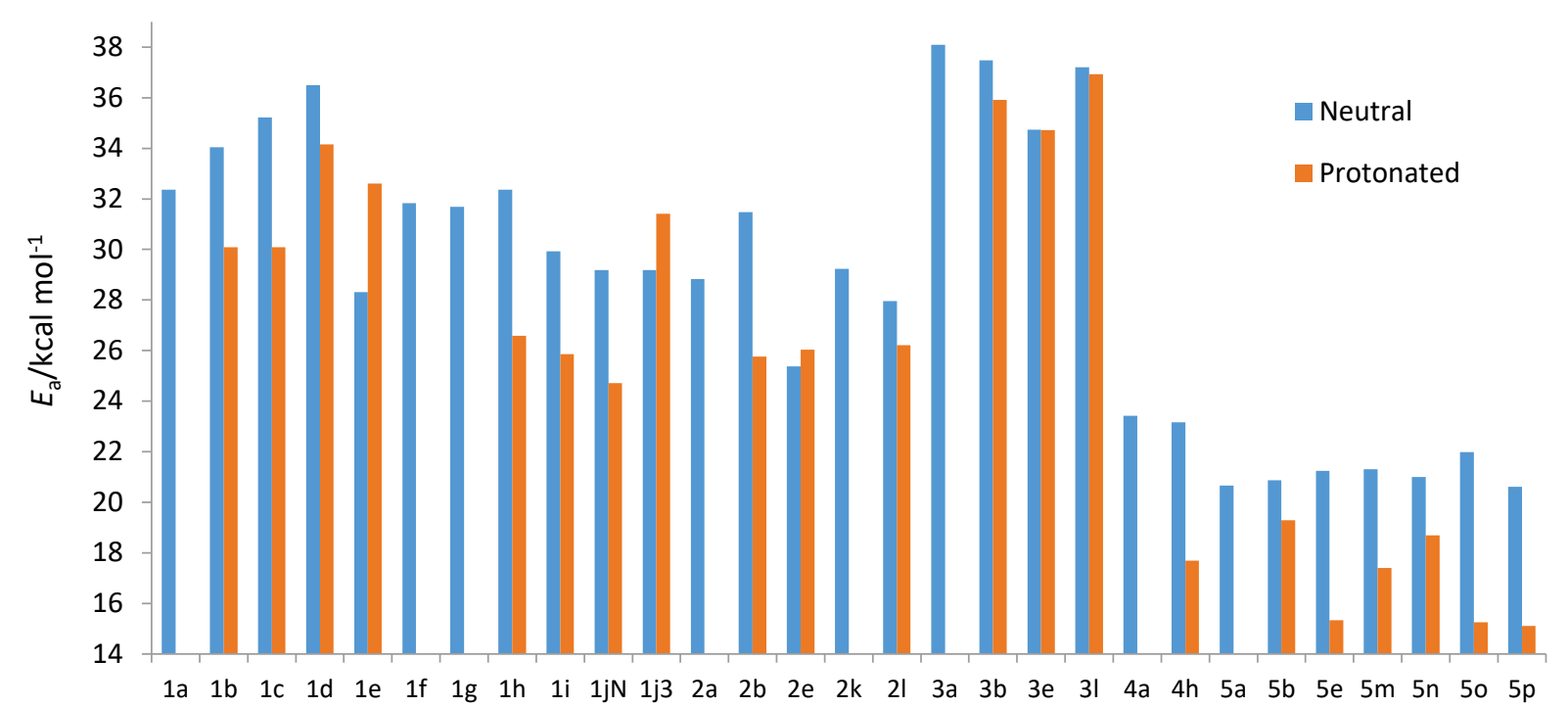

Dienes

Figure 4. Activation energies for neutral and protonated DA reactions $\left(E_{\mathrm{a}}\right.$ and $\left.E_{a} H^{+}\right)$.

\section{Computational Details}

All the calculations were carried out with Gaussian 09[32] suite of programs. Geometry optimizations and energy calculations were performed with the B3LYP method ${ }^{[33,34]}$ and the $6-31 \mathrm{G}(\mathrm{d})$ basis set. Frequency analysis was used to verify the stationary points as minima or saddle points. Intrinsic reaction coordinate (IRC) calculations were carried out at the B3LYP/6-31G(d) level to verify the connections of the first-order saddle points with the local minima which were found on the potential energy surface. The frontier molecular orbitals (FMOs) and their energies were computed at the HF/6-31G(d) level using the B3LYP/6$31 \mathrm{G}(\mathrm{d})$ geometries. The calculations of the nucleusindependent chemical shift (NICS) ${ }^{[35]}$ were performed by the $B 3 L Y P / 6-311+G(d)$ method in the point $1 \AA$ above the ring center. Ring center was determined by $\mathrm{AIM}^{[36]}$ method using B3LYP/6-31G(d) densities. Molden ${ }^{[37]}$ program was used for visualization and geometry manipulations.

Acknowledgements. The authors acknowledge funding by the Croatian Science Foundation grant No. IP-2018-01-3298, Cycloaddition strategies towards polycyclic guanidines (CycloGu). The calculations were performed on the Isabella computational cluster (isabella.srce.hr) at the Zagreb University Computing Center (SRCE).

Supplementary Information. Supporting information to the paper is attached to the electronic version of the article at: https://doi.org/10.5562/cca3570.

PDF files with attached documents are best viewed with Adobe Acrobat Reader which is free and can be downloaded from Adobe's web site.

\section{REFERENCES}

[1] D. Margetić, Physico-Chemical Properties of Organosuperbases, in Superbases for Organic Synthesis: Guanidines, Amidines, Phosphazenes and Related Organocatalysts, T. Ishikawa (Ed.), Wiley, Chichester, 2009, Chapter 2, pp. 9-48. https://doi.org/10.1002/9780470740859.ch2

[2] K. A. Schug, W. Lindner, Chem Rev. 2005, 105, 67-114. https://doi.org/10.1021/cr040603j

[3] P. J. Bailey, S. Pace, Coord. Chem. Rev. 2001, 214, 91-141.

https://doi.org/10.1016/S0010-8545(00)00389-1

[4] F. Sączewski, Ł. Balewski. Expert. Opin. Ther. Pat. 2013, 23, 965-995.

https://doi.org/10.1517/13543776.2013.788645

[5] P. Selig, Synthesis 2013, 45, 703-718. https://doi.org/10.1055/s-0032-1318154

[6] D. Margetić, Cycloadditions of guanidines, in Cycloaddition Reactions: Advances in Research and Applications, D. Margetić (ed.), Nova Science Publishers, Hauppauge, ISBN: 9781536154207, New York 2019, Chapter 7, pp. 243-280.

https://novapublishers.com/shop/cycloadditionreactions-advances-in-research-and-applications/

[7] D. Margetić, R. N. Warrener, Croat. Chem. Acta. 2003, 76, 357-363. https://hrcak.srce.hr/103199

[8] R. N. Warrener, D. Margetić, G. Sun, Tetrahedron Lett. 2001, 42, 4263-4265. https://doi.org/10.1016/S0040-4039(01)00665-7 
[9] D. Margetić, M. Eckert-Maksić, New J. Chem. 2006, 30, 1149-1154. https://doi.org/10.1039/b515810a

[10] D. Margetić, R. N. Warrener, P. W. Dibble, J. Mol. Modelling 2004, 10, 87-92. https://doi.org/10.1007/s00894-003-0143-z

[11] Z. Glasovac, M. Eckert-Maksić, Austral. J. Chem. 2014, 67, 1056-1062.

https://doi.org/10.1071/CH14182

M. Eckert-Maksić, Z. Glasovac, P. Trošelj, A. Kütt, T. Rodima, I. Koppel, I. A. Koppel, Eur. J. Org. Chem. 2008, 30, 5176-5184.

https://doi.org/10.1002/ejoc.200800673

[12] F. Fringuelli, A. Taticchi (Eds.), The Diels-Alder Reaction: Selected Practical Methods, Wiley, Chichester, 2002.

https://doi.org/10.1002/0470845813

[13] I. Antol, Z. Glasovac, D. Margetić, R. Crespo-Otero, M. Barbatti, J. Phys. Chem. A 2016, 120, 7088-7100. https://doi.org/10.1021/acs.jpca.6b05180

[14] K. Fukui, Theory of Orientation and Stereoselection, Springer-Verlag, Berlin, 1975.

https://doi.org/10.1007/978-3-642-61917-5

[15] I. Fleming, Molecular Orbitals and Organic Chemical Reactions Wiley, Chichester, 2009. https://doi.org/10.1002/9780470684306

[16] Z. Chen, M. L. Trudell, Chem. Rev. 1996, 96, 11791194. https://doi.org/10.1021/cr9500388

[17] J. R. Malpass, G. Sun, J. Fawcett, R. N. Warrener, Tetrahedron Lett. 1998, 39, 3083-3086. https://doi.org/10.1016/S0040-4039(98)00364-5

[18] S. Yu, H. M. de Bruijn, D. Svatunek, T. A. Hamlin, F. M. Bickelhaupt, ChemistryOpen 2018, 7, 995-1004. https://doi.org/10.1002/open.201800193

[19] K. N. Houk, Acc. Chem. Res. 1975, 8, 361-369. https://doi.org/10.1021/ar50095a001

[20] K. N. Houk, L. L. Munchausen, J. Am. Chem. Soc. 1976, 98, 937-946. https://doi.org/10.1021/ja00420a012

[21] K. N. Houk, Y. Li, D. Evanseck, Angew. Chem. Int. Ed. Engl. 1992, 31, 682-708. https://doi.org/10.1002/anie.199206821

[22] R. D. J. Froese, J. M. Coxon, S. C. West, K. Morokuma, J. Org. Chem. 1997, 62, 6991-6996. https://doi.org/10.1021/jo970811u
[23] M. Linder, T. Brinck, Phys. Chem. Chem. Phys. 2013, 15, 5108-5114.

https://doi.org/10.1039/c3cp44319a

[24] The inclusion of dispersion interaction with Grimme D3 correction had only minor impact on the results (Supporting Information Tables 12 and 13).

[25] E. Wenkert, P. D. R. Moeller, S. R. Piettre, J. Am. Chem. Soc. 1988, 110, 7188-7194. https://doi.org/10.1021/ja00229a039

[26] R. Katritzky, Reactivity of Five-membered ring with one heteroatom, in Handbook of Heterocyclic Chemistry, Pergamon, Oxford 1985. https://doi.org/10.1016/B978-0-08-030726-8.50018-X

[27] R. R. Gupta, M. Kumar, V. Gupta, Heterocyclic Chemistry II. Five-Membered Heterocycles, Springer, Heidelberg 1999. https://doi.org/10.1007/978-3-662-07757-3_2

[28] B. S. Juršić, J. Chem. Soc., Perkin Trans. 2 1999, 131136. https://doi.org/10.1039/a803740j

[29] L. Lu, S. S. Yang, Z. Wang, R. G. Cooks, M. N. Eberlin, J. Mass Spectrom. 1995, 30, 581-594. https://doi.org/10.1002/jms.1190300409

[30] C. E. Schmaunz, P. Mayer, K. T. Wanner, Synthesis 2014, 46, 1630-1638. https://doi.org/10.1055/s-0033-1341044

[31] S.-Y. Tang, J. Shi, Q.-X. Guo, Org. Biomol. Chem. 2012, 10, 2673-2682. https://doi.org/10.1039/c2ob07079k

[32] M. J. Frisch, et al., Gaussian 09, revision D.01; Gaussian, Inc.: Wallingford, CT, 2009.

[33] D. Becke, J. Chem. Phys. 1993, 98, 5648-5652. https://doi.org/10.1063/1.464913

[34] C. Lee, W. Yang, R. G. Parr, Phys. Rev. B 1988, 37, 785-789. https://doi.org/10.1103/PhysRevB.37.785

[35] P. v. R. Schleyer, C. Maerker, A. Dransfeld, H. Jiao, N. J. R. van E. Hommes, J. Am. Chem. Soc. 1996, 118, 6317-6318. https://doi.org/10.1021/ja960582d

[36] R. F. W. Bader, Atoms in Molecules: A Quantum Theory, Clarendon Press, ISBN: 9780198558651 Oxford, 1990.

[37] G. Schaftenaar, J. H. Noordik, J. Comp. Aided Mol. Design 2000, 14, 123-134. https://doi.org/10.1023/A:1008193805436 